\title{
Inheritance of Normal Pod Development in Bean Golden Yellow Mosaic Resistant Common Bean
}

\author{
Maricelis Acevedo Román, Albeiro Molina Castañeda, Juan Carlos Angel Sánchez, \\ Carlos Germán Muñoz, and James S. Beaver ${ }^{1}$ \\ Department of Agronomy and Soils, University of Puerto Rico, Mayaguez, PR 00681
}

\begin{abstract}
AdDitional INDEX words. Phaseolus vulgaris, disease resistance, begomovirus
Abstract. The inheritance of resistance to bean golden yellow mosaic virus (BGYMV) was studied in common beans (Phaseolus vulgaris L.). The original cross was made between breeding line PR9556-158, which produces deformed pods when infected with BGYMV, and PR9556-171, which has normal pod development when inoculated with the virus. Pod type was evaluated on plants from six generations (parental lines, $F_{1}, F_{2}, F_{2: 3}, F_{3: 4}$, and backcrosses of the $F_{1}$ to both parents) at mid-pod fill $(R 8), \approx 65$ days after planting. The segregation patterns from the $F_{2}, F_{2: 3}, F_{3: 4}$, and backcross populations were consistent with the hypothesis that a single dominant gene confers normal pod development in PR9556-171. When inoculated with BGYMV, the deformed pods of PR9556-158 produced fewer seeds per pod than PR9556-171, resulting in lower seed yield. The gene symbol Bgp-1 has been assigned for this dominant resistance gene that controls the normal pod reaction to BGYMV in common bean.
\end{abstract}

Bean golden yellow mosaic, caused by a whitefly [Bemisia tabaci (Gennadius)] transmitted begomovirus, is an important disease of common bean in the lowland tropics (Morales and Niessen, 1988) and subtropics (Blair et al., 1995). Bean production in regions threatened by bean golden yellow mosaic often requires the use of systemic insecticides that increase production costs and may represent health hazards (Singh et al., 2000).

Bean breeders have had success in the development and release of bean golden yellow mosaic virus (BGYMV)-resistant varieties. The single recessive gene, bgm- 1 , is present in BGYMV-resistant varieties of Middle American origin, such as the small red variety 'Don Silvio' and the black-seeded variety 'Turbo III' (Urrea et a1., 1996). A second recessive gene, bgm-2, of Andean origin is found in the International Center for Tropical Agriculture (CIAT) breeding line DOR303 (Velez et al., 1998). Both genes provide resistance to leaf chlorosis in bean plants inoculated with the virus. A need exists to identify new genes for resistance to BGYMV to broaden the genetic base of resistance to this disease. Under severe disease pressure, lines with the bgm- 1 or $b g m-2$ genes can produce deformed pods. This deformation reduces yield potential and renders snap beans commercially unacceptable. The objective of this research was to study the inheritance of normal pod development in bean plants inoculated with BGYMV. This trait complements the resistance to leaf chlorosis in bean lines with the $b g m-1$ or $b g m-2$ gene.

\section{Materials and Methods}

Two $\mathrm{F}_{3}$ sister lines from the cross DOR364' / WBB20-1// 'Don Silvio' were selected for a nonchlorotic leaf reaction to BGYMV in a nursery planted at Isabela, Puerto Rico, in June 1995. At harvest maturity these lines were found to differ in degree of pod deformation caused by the virus. Most of the pods on line PR9556-158 were deformed, whereas pod development was normal on PR9556-171. Individual plants were harvested from each $\mathrm{F}_{3}$ plant row.

To confirm the field reaction, $\mathrm{twoF}_{3: 4}$ seeds from each individual plant selection were planted in Jan. 1996 in a greenhouse at the

Received for publication 15 Jan. 2004. Accepted for publication 14 Mar. 2004. ${ }^{1}$ To whom reprint requests should be addressed.
Univ. of Puerto Rico, Mayaguez, and inoculated with viruliferous whiteflies using the technique described by Adames-Mora et al. (1996). At $20 \mathrm{~d}$ after inoculation, leaf symptoms on the plants were originally evaluated using the standard 1-9 evaluation scale recommended by CIAT, where $1=$ no symptoms and $9=$ severely chlorotic leaves (Van Schoonhoven and Pastor-Corrales, 1987). Pod deformation was evaluated at mid-pod fill (R8) using a scale from 1 to 9 where $1=$ normal pod development and $9=$ all pods severely deformed. Following the CIAT 1-9 scale, plants scored 1-3 are considered to be resistant.

Five $\mathrm{F}_{3: 4}$ seeds of each individual plant selection were planted in Jan. 1996 in another greenhouse that was free of BGYMV in order to develop populations for an inheritance study. The parents and five $F_{1}$ plants from the cross between PR9556-158 and PR9556-171 were planted in the greenhouse in Apr. 1996 to produce $F_{2}$ seed and backcrosses of the $F_{1}$ with both parents. In July 1996, an experiment was planted in a greenhouse on the Univ. of Puerto Rico, Mayaguez, to evaluate the leaf and pod reaction of the parental lines, $F_{1}, F_{2}$, and backcrosses of $F_{1}$ to both parents to BGYMV. Each seed was planted in an individual 15-cm-diameter pot. Eight seeds of each parent, seven seeds of the $F_{1}$ and each backcross, and $38 F_{2}$ seeds were planted. Five seed of 'Top Crop' were planted as a susceptible control. The plants were inoculated with viruliferous whiteflies at $8 \mathrm{~d}$ after planting and leaf symptoms on the plants were evaluated at 20 $\mathrm{d}$ after inoculation. Pod deformation was evaluated at mid-pod fill (R8) using the previously described 1-9 scale. Pod scores from 1 to 3 were considered normal, whereas scores from 4 to 9 were considered deformed. The chi-square statistic was used to test for goodness-of-fit to expected segregation ratios. At harvest maturity, the number of pods, number of seeds per pod, and seed weight were recorded for the parents and $F_{1}$ plants. The experimental design was completely randomized with seven to eight replications. An LSD (0.05) for unbalanced data was used to compare means.

In Dec. 1996, four seeds of each parent, PR9556-158 and PR9556-171, and 59 seeds of seven $\mathrm{F}_{2: 3}$ lines were planted in another greenhouse experiment. The plants were inoculated with viruliferous flies at $8 \mathrm{~d}$ after planting and leaf symptoms on the plants were evaluated at $20 \mathrm{~d}$ after inoculation. Pod deformation was evaluated at mid-pod fill (R8). The chi-square statistic was 
used to test for goodness-of-fit to expected segregation ratios.

In 1998, an additional population of $86 \mathrm{~F}_{2}$ seeds from the cross PR9556-158 / PR9556-171 was evaluated in the greenhouse for leaf and pod reaction to BGYMV. Inoculation and evaluation techniques were the same as was previously described. The chisquare statistic was used to test for goodness-of-fit to expected segregation ratios.

A field trial was planted on 25 Feb. 2000 at the Alzamora Farm at the Univ. of Puerto Rico, Mayaguez. Eighty-one $\mathrm{F}_{3: 4}$ lines from the cross PR9556-158 / PR9556-171 were evaluated. The trial also included three replications of the parents and the BGYMVsusceptible cultivar Mayflower. Fifteen seeds were planted in each 1-m row length. Rows were spaced at $0.75 \mathrm{~m}$. Spreader rows of 'Mayflower' were planted on the border of the nursery in Dec. 1999. When the trial was planted, many of the plants in the spreader rows were infected with BGYMV. Each row was evaluated on 25 Apr. 2000 for leaf and pod reaction. Evaluation techniques were the same as was previously described. The chisquare statistic was used to test for goodness-of-fit to expected segregation ratios.

A crossing block was planted at the Substation near Isabela, Puerto Rico, in Nov. 2001 in order to develop additional populations to study the inheritance of resistance to pod deformation caused by BGYMV. All of the parents had the recessive bgm-1 gene for resistance to BGYMV. PR9556-158 produces deformed pods in the presence of BGYMV, whereas PR9556-171 and the cultivar Don Silvio (DOR 482) produce normal pods. Twentysix $F_{1}$ plants from the crosses 'PR9556-171/PR9556-158' and 'PR9556-158/DOR 482' were planted in a screenhouse in June 2001 at a Substation near Adjuntas, Puerto Rico. Each $F_{1}$ seed was planted in a 15 -cm-diameter pot and fertilized with $0.2 \mathrm{~g}$ of $16 \mathrm{~N}-7 \mathrm{P}-13.3 \mathrm{~K}$ granular fertilizer. An automatic irrigation system was used to water the plants. The $\mathrm{F}_{2}$ seed from each $\mathrm{F}_{1}$ plant was harvested separately.

In June $2002,440 \mathrm{~F}_{2}$ plants from each population were planted at the Isabela Substation. The $\mathrm{F}_{2}$ plants were planted in $2201-\mathrm{m}$ rows with a spacing of $0.6 \mathrm{~m}$ between rows and $\approx 0.1 \mathrm{~m}$ between plants within the rows. The parents, four susceptible and four resistant $\mathrm{F}_{7}$ lines from the cross PR9556-158/PR9556-171, were included in the nursery as controls. Two replications of each control was planted with each population. The susceptible cultivar Top Crop was planted at five-row intervals to serve as a spreader for BGYM.

'Top Crop' was mechanically inoculated with BGYMV at $10 \mathrm{~d}$ after planting and symptoms began to appear $\approx 10 \mathrm{~d}$ after inoculation. Natural whitefly populations were used to infect the $\mathrm{F}_{2}$ plants and controls.

Each $\mathrm{F}_{2}$ plant and each control row was evaluated for the presence or absence of leaf chlorosis and degree of pod deformation at 45 and $60 \mathrm{~d}$ after planting. The number of $\mathrm{F}_{2}$ plants with little or no deformation (1-3) and plants with deformed pods (4-9) were counted. A chi-square statistic was used to test for goodness-of-fit to expected segregation ratios.

Twenty-eight $\mathrm{F}_{2: 3}$ lines from the cross 'PR9556-158 / PR9556171 ' were planted at the Isabela Substation on 12 June 2003. In the $\mathrm{F}_{2}$ generation, all of the plants had no chlorosis and normal pod development in the presence of BGYMV. The lines were planted in $1-\mathrm{m}$ row lengths spaced $0.6 \mathrm{~m}$ apart with a within row spacing of $\approx 0.1 \mathrm{~m}$. From two to four rows of each line were planted depending on the availability of the seed. The susceptible bean cultivar Top Crop was planted every 10 rows to serve as a spreader for BGYMV. About 1 week after emergence, the 'Top
Crop' plants were mechanically inoculated with BGYMV using the previously described procedures. Eight weeks after planting, individual plants were evaluated for the expression of pod deformation. An $\mathrm{F}_{2: 3}$ line having at least one plant with deformed pods was considered to be segregating. A chi-square test was used to test for goodness-of-fit to expected segregation ratios.

\section{Results and Discussion}

Both PR9556-158 and PR9556-171 have a nonchlorotic leaf reaction similar to their parent 'Don Silvio' (DOR 482) in the presence of BGYMV. The presence of the recessive gene $\mathrm{bgm-1}$ (Velez et al., 1998) in both lines was confirmed by the presence of the linked codominant RAPD marker R2570/530 (Urrea et al., 1996). Both lines also have a QTL for BGYMV resistance established by the presence of the SCAR marker SW12 (Miklas et al., 2000). $\mathrm{F}_{3: 4}$ plants from the line PR9556-158 produced deformed pods, whereas $\mathrm{F}_{3: 4}$ plants from PR9556-171 had normal pod development in the greenhouse experiments planted in Jan. and Apr. 1996 (Table 1). Both lines had normal pod development in the greenhouse where no BGYMV was present.

All of the $F_{1}$ plants from the cross PR9566-158 / PR9556-171 had normal pod development. The $\mathrm{F}_{2}$ population fit a 3:1 segregation pattern with 27 plants with normal pod development and 11 plants with deformed pods (Table 1). All of the plants from the backcross with PR9556-171 were normal, whereas plants from the backcross with PR9566-158 fit a 1:1 ratio for normal and deformed pods (Table 1). These results support the hypothesis that normal pod development in the presence of BGYM is controlled by a single dominant gene, for which the symbol Bgp (Bean golden pod) has been approved by the Bean Genetics Committee.

The $\mathrm{F}_{2: 3}$ lines derived from $\mathrm{F}_{2}$ plants with deformed pods also had deformed pods, whereas $\mathrm{F}_{2: 3}$ lines $2,3,4$, and 5 from plants with normal pods produced normal pods (Table 2 ). The $\mathrm{F}_{2: 3}$ lines 6 and 7 segregated for normal and deformed pods and the pattern of segregation fit a 3:1 ratio with 15 plants with normal pods and five plants with deformed pods (Table 2). These results are in agreement with the hypothesis that a single dominant gene controls normal pod development in the presence of BGYMV.

The mean pod deformation score for $F_{1}$ plants was similar to the mean pod deformation score of PR9556-171, which would be expected if normal pod development were a simple dominant trait (Table 3). PR9556-171 and the $F_{1}$ plants produced greater seed weight per plant than PR9556-158, the parent that produced deformed pods (Table 3). Most of the difference in seed yield was attributed to a greater number of seed per pod produced by PR9556-171 and the $F_{1}$ plants (Table 3). These results demonstrate the adverse effect that BGYMV can have on seed yield even when the $b g m-1$ gene is present.

Results from the 1998 greenhouse evaluation of the $\mathrm{F}_{2}$ population further support the hypothesis that normal pod development in the presence of BGYMV is a single dominant trait. There were $64 \mathrm{~F}_{2}$ plants with normal pods and 22 plants with deformed pods (Table 4). The chi-square value for a 3:1 segregation pattern for normal : deformed pods was 0.015 with a $P$ between 0.9 and 0.95 .

Segregation patterns of the $\mathrm{F}_{3: 4}$ lines in the field trial further support the hypothesis of a simple dominant gene for normal pod development in the presence of BGYMV. A total of 34 rows of $F_{3: 4}$ plants had normal pods, whereas 47 rows had one or more plants with deformed pods (data not shown). The expected segregation pattern for a simple dominant trait would be would be $3 / 8$ of the 
Table 1. Classification of parental, $\mathrm{F}_{1}, \mathrm{~F}_{2}$, and backcross $(\mathrm{BC})$ generations of common bean progeny from the cross PR9556-158 / PR9556-171 for pod deformation on plants inoculated in 1996 with bean golden yellow mosaic virus (BGYMV)z in the greenhouse at the Univ. of Puerto Rico, Mayaguez.

\begin{tabular}{|c|c|c|c|c|c|}
\hline \multirow[b]{2}{*}{ Generation } & \multicolumn{2}{|c|}{ Pod type } & \multirow{2}{*}{$\begin{array}{c}\text { Expected } \\
\text { ratio }\end{array}$} & \multirow[b]{2}{*}{$\chi^{2}$} & \multirow[b]{2}{*}{$P$} \\
\hline & Normal & Deformed & & & \\
\hline PR9556-158 & 0 & 8 & & & \\
\hline PR9556-171 & 8 & 0 & & & \\
\hline $\mathrm{F}_{1}$ (PR9556-158 / PR9556-171) & 7 & 0 & & & \\
\hline $\mathrm{F}_{2}$ (PR9556-158 / PR9556-171) & 27 & 11 & $3: 1$ & 0.32 & 0.57 \\
\hline $\mathrm{BC}\left(\mathrm{F}_{1} / \mathrm{PR} 9556-158\right)$ & 4 & 2 & $1: 1$ & 0.66 & 0.42 \\
\hline $\mathrm{BC}\left(\mathrm{F}_{1} / \mathrm{PR} 9556-171\right)$ & 5 & 0 & $1: 0$ & & \\
\hline
\end{tabular}

${ }^{2}$ The genetic hypothesis is that PR9556-171 carries a dominant gene (Bgp-1) for resistance to BGYMVinduced pod deformation.

Table 2. Classification of parental and $\mathrm{F}_{2: 3}$ bean lines from the cross PR9556-158 / PR9556-171 for pod deformation on plants inoculated in 1996 with Bean golden yellow mosaic virus (BGYMV) ${ }^{\mathrm{z}}$ in the greenhouse at the Univ. of Puerto Rico, Mayaguez.

\begin{tabular}{|c|c|c|c|c|c|c|}
\hline \multirow[b]{2}{*}{ Generation } & \multirow{2}{*}{$\begin{array}{c}\mathrm{F}_{2} \text { reaction to } \\
\text { BGYMV }\end{array}$} & \multicolumn{2}{|c|}{ Pod type } & \multirow{2}{*}{$\begin{array}{c}\text { Expected } \\
\text { ratio }\end{array}$} & \multirow[b]{2}{*}{$\chi^{2}$} & \multirow[b]{2}{*}{$P$} \\
\hline & & Normal & Deformed & & & \\
\hline PR9556-158 & Deformed & 0 & 4 & & & \\
\hline PR9556-171 & Normal & 4 & 0 & & & \\
\hline $\mathrm{F}_{2: 3}$ line 1 & Normal & 0 & 4 & & & \\
\hline $\mathrm{F}_{2: 3}$ line 2 & Normal & 11 & 0 & & & \\
\hline $\mathrm{F}_{2: 3}$ line 3 & Normal & 10 & 0 & & & \\
\hline $\mathrm{F}_{2: 3}$ line 4 & Normal & 8 & 0 & & & \\
\hline $\mathrm{F}_{2: 3}$ line 5 & Normal & 10 & 0 & & & \\
\hline $\mathrm{F}_{2: 3}$ line 6 & Normal & 8 & 3 & $3: 1$ & 0.030 & 0.86 \\
\hline $\mathrm{F}_{2: 3}$ line 7 & Normal & 7 & 2 & $3: 1$ & 0.037 & 0.84 \\
\hline
\end{tabular}

zThe genetic hypothesis is that PR9556-158 carries a dominant gene (Bgp-1) for resistance to BGYMV-induced pod deformation.

Table 3. Mean pod deformation, mean seed weight per plant, mean number of pods per plant and mean number of seeds per pod of parental and $\mathrm{F}_{1}$ generations from the cross PR9556-158 / PR9556-171 on plants inoculated in 1996 with bean golden yellow mosaic virus (BGYMV) in the greenhouse at the Univ. of Puerto Rico, Mayaguez.

\begin{tabular}{lcccc}
\hline Mean pod & $\begin{array}{c}\text { Mean seed } \\
\text { deformation } \\
\text { score } \\
(1-9)\end{array}$ & $\begin{array}{c}\text { wt } \\
\text { (g/plant) }\end{array}$ & $\begin{array}{c}\text { Mean no. } \\
\text { of pods } \\
\text { (no./plant) }\end{array}$ & $\begin{array}{c}\text { Mean no. } \\
\text { of seeds } \\
\text { (no./pod) }\end{array}$ \\
\hline PR9556-158 & 6.6 & 3.5 & 8.9 & 2.5 \\
PR9556-171 & 2.3 & 6.5 & 10.5 & 3.6 \\
$\mathrm{~F}_{1}$ & 2.7 & 7.5 & 14.2 & 3.5 \\
$\mathrm{LSD}_{0.05}$ & 0.6 & NS & NS & 0.6 \\
\hline
\end{tabular}

Table 4. Inheritance ${ }^{z}$ of pod deformation produced by bean golden yellow mosaic virus (BGYMV) in an $\mathrm{F}_{2}$ population from the cross PR9556-158 / PR9556-171 planted in 1998 in a greenhouse at the Univ. of Puerto Rico, Mayaguez, and $F_{2}$ populations from the crosses PR9556-158 / PR9556-171 and PR9556-158 / DOR 482 planted during Summer 2002 at the Isabela, Puerto Rico, Substation.

\begin{tabular}{|c|c|c|c|c|c|c|}
\hline \multirow[b]{2}{*}{ Population } & \multicolumn{2}{|c|}{ Observed } & \multicolumn{2}{|c|}{ Expected } & \multirow[b]{2}{*}{$\chi^{2}$} & \multirow[b]{2}{*}{$P$} \\
\hline & $\begin{array}{c}\text { Normal } \\
\text { pods } \\
\text { (no.) }\end{array}$ & $\begin{array}{c}\text { Deformed } \\
\text { pods } \\
\text { (no.) }\end{array}$ & $\begin{array}{c}\text { Normal } \\
\text { pods } \\
\text { (no.) }\end{array}$ & $\begin{array}{c}\text { Deformed } \\
\text { pods } \\
\text { (no.) }\end{array}$ & & \\
\hline $\mathrm{F}_{2}$ (PR9556-158 / PR9556-171) & 64 & 22 & 64.5 & 21.5 & 0.015 & $0.9-0.95$ \\
\hline $\mathrm{F}_{2}$ (PR9556-158 / PR9556-171) & 176 & 62 & 178.5 & 59.5 & 0.0691 & 0.7927 \\
\hline $\mathrm{F}_{2}(\mathrm{PR} 9556-158 / \mathrm{DOR} 482)$ & 230 & 76 & 229.5 & 76.5 & 0.0022 & 0.9627 \\
\hline
\end{tabular}

zThe inheritance of resistance to pod deformation induced by BGYMV is hypothesized to be conferred by a single dominant gene (Bgp-1). 
rows with normal pods and 5/8 of the rows with either deformed pods or segregating for the trait. The chi-square value was 0.676 with a $P$ between 0.25 and 0.50 .

Mechanical inoculation with BGYMV in the 2002 field trial resulted in a high incidence of infection in the 'Top Crop' spreader rows. The resistant parents, PR9556-171 and DOR482, had neither chlorotic leaves nor deformed pods, whereas the susceptible parent, PR9556-158, had healthy leaves and deformed pods. These results are in agreement with previous field and greenhouse studies conducted in Puerto Rico.

In the PR9556-158 / DOR482 $\mathrm{F}_{2}$ population, 76 plants had deformed pods and 230 plants had normal pods. The chi-square test accepted the Ho for a 3 (resistant) : 1 (susceptible) pattern of segregation (Table 4). In the PR9556-158 / PR9556-171 $\mathrm{F}_{2}$ population 62 plants had deformed pods and 176 plants had normal pods. The results from the chi-square test were also in agreement with the hypothesis that a single dominant gene controls normal pod development (Table 4). These results also suggest that the resistance to pod deformation was originally derived from CIAT breeding line DOR 482. This breeding line, which combines the recessive gene $b g m-1$, the QTL SW12, and $B g p-1$, has a high level of resistance to BGYMV when evaluated in Central America and the Caribbean.

Seventeen of the $28 \mathrm{~F}_{2: 3}$ lines from the cross PR9556-158 / PR9556-171 planted at the Isabela Substation in the 2003 field trial segregated for the pod deformation trait (data not shown). The chi-square test accepted the Ho with a $P$ between 0.05 and 0.10 for the expected ratio of 3 (segregating or susceptible $F_{2: 3}$ rows) : 1 ( resistant $\mathrm{F}_{2: 3}$ rows) for resistance conferred by a single dominant gene.
BGYMV can cause pod deformation in bean lines with or without the recessive gene $b g m-1$ for resistance to leaf chlorosis. In order to develop lines that have resistance to both leaf chlorosis and pod deformation it is necessary to combine the bgm-1 and Bgp-1 genes.

\section{Literature Cited}

Adames-Mora, C., J.S. Beaver, and O. Diaz. 1996. A methodology for screening for bean golden yellow mosaic virus resistance in the greenhouse (in Spanish). J. Agr. of the Univ. of Puerto Rico 80:65-72.

Blair, M.W., M.J. Bassett, A.M. Abouzid, E. Hiebert, J.E. Polston, R.T. McMillan, W. Graves, and M. Lamberts. 1995. Occurrence of bean golden mosaic virus in Florida. Plant Dis. 79:529-533.

Miklas, P.N., V. Stone, M.J. Daly, J.R. Stavely, J.R. Steadman, M.J. Bassett, R. Delorme, and J.S. Beaver. 2000. Bacterial, fungal and viral disease resistance loci mapped in a recombinant inbred common bean population (Dorado/XAN176). J. Amer. Soc. Hort Sci. 125:476-481.

Morales. F.J. and A.I. Niessen. 1988. Comparative responses of selected Phaseolus vulgaris L. germplasm inoculated artificially and naturally with bean golden mosaic virus. Plant Dis. 72:1020-1023.

Singh, S.P., F.J. Morales, P.N. Miklas, and H. Terán. 2000. Selection for bean golden mosaic resistance in intra- and interracial bean populations. Crop Sci. 40:1565-1572.

Urrea, C.A., P.N. Miklas, J.S. Beaver, and R.H. Riley. 1996. A codominant randomly amplified polymorphic DNA marker useful for indirect selection of bean golden mosaic virus resistance in common bean. J. Amer. Soc. Hort. Sci. 121:1035-1039.

Van Schoonhoven, A. and M.A. Pastor Corrales. 1987. Standard system for the evaluation of bean germplasm. CIAT, Cali, Colombia.

Velez. J .J., M.J. Bassett, J.S. Beaver, and A. Molina. 1998. Inheritance of resistance to bean golden mosaic virus in common bean. J. Amer. Soc. Hort. Sci. 123:628-631. 